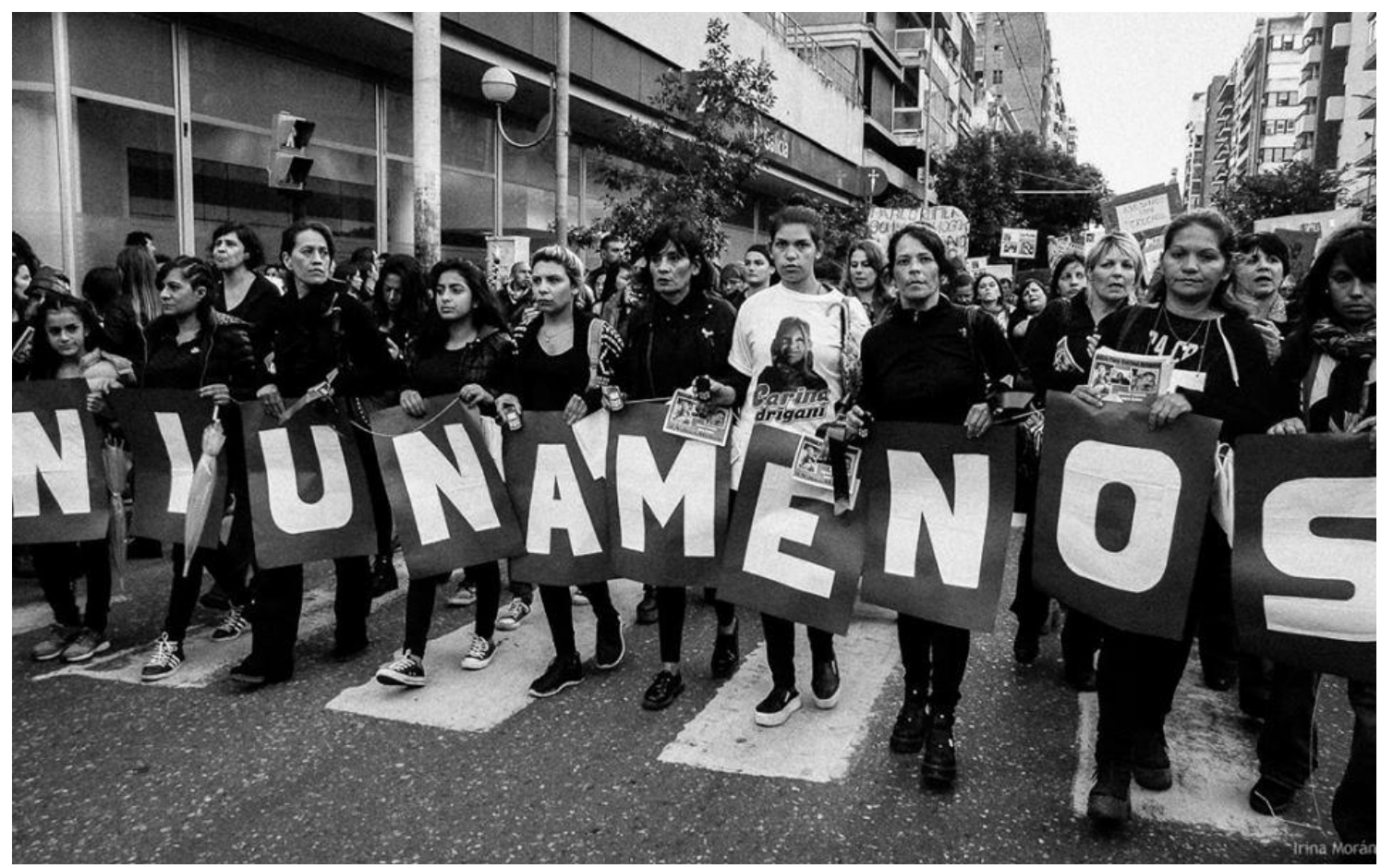

FOTOS: Irina Morán - Revista Alfilo - Periodista Feminista. Militante de Ni Una Menos Córdoba y Mujeres por un parto Respetado 


\title{
FEMINISMOS Y EDUCACIÓN: OTROS LENGUAJES QUE PROPORCIONAN SENTIDO AL INTERCAMBIO
}

\author{
Liliana Kremer ${ }^{1}$
}

Resumen: En este artículo abordamos dispositivos que los feminismos - como herramientas reflexivas y de acción - sirven para conmover y contribuir a que la educación sea un motor de transformaciones y de nuevos retos. Tratamos su contribución a la construcción de una educación que recupere y se consolide desde las diferencias -, la inclusión, el reconocimiento y la solidaridad, la libertad. Los aportes feministas nos llevan a concebir una pedagogía que ayude a interrogarse, a dudar, a preguntar (nos), a co-crear y construir, en donde se escuchen los silencios y se nos permita reír. Proponemos como herramientas nodales el diálogo, el construccionismo, la interculturalidad y las narrativas como perspectivas que permiten hacer de nuestras prácticas, practicas fundadas, reflexivas y situadas. Presentamos el Colectivo de Mujeres del Chaco como un caso explícito de territorio cooperativo de construcción de saberes compartidos.

Palabras claves: Educación transformativa. Narrativas. Diferencias. Mujeres organizadas. Territorios compartidos de saberes.

\section{FEMINISMS AND EDUCATION: OTHER LANGUAGES THAT OFFER MEANING TO THE EXCHANGE}

\begin{abstract}
In this article, we approach devices that feminisms - as reflexive and action tools - serve to move and contribute to making education an engine of transformations and new challenges. We treat your contribution to the construction of an education that recovers and consolidates - from differences -, inclusion, recognition and solidarity, freedom. Feminist contributions lead us to conceive a pedagogy that helps to interrogate, to doubt, to ask (us), to co-create and to build, where silences are heard and we are allowed to laugh. We propose as dialogue tools, constructionism, interculturality and narratives as perspectives that allow us to make our practices, founded, reflective and situated practices. We present the Colectivo de Mujeres del Chaco as an explicit case of cooperative territory for the construction of shared knowledge.
\end{abstract}

Keywords: Transformative education. Narratives. Differences. Organized women. Shared territories of knowledge.

\section{INTRODUCCIÓN}

Este artículo surge de mis intervenciones con el Colectivo de Mujeres del Chaco Americano y con otras organizaciones de base en el territorio; así como de mi reflexión en torno a ellas, basadas en prácticas educativas que buscan a generar transformaciones sociales; con soportes teóricos recogidos del feminismo, el construccionismo, los procesos dialógicos y las narrativas.

Al posicionarme desde los feminismos - desde sus múltiples expresiones de pensamiento, críticas sociales y políticas; así como de sus distintas experiencias y modalidades prácticas en diversos espacios sociales - adherimos a enfoques que comparten: el combate por la equidad y la emancipación, la superación de dependencias, estereotipos y la ruptura con relaciones de dominación.

Abordar la educación con aportes de marcos teóricos feministas, significa

\footnotetext{
1 Profesora titular Educación y Trabajo Social; Directora Proyecto investigación; Dra en Estudios
} Sociales Agrarios; Coordinadora Colectivo de Mujeres del chaco Americano. 
caminar hacia una inclusión e institucionalización del enfoque de género con un fuerte compromiso, y, desde allí, apostar a la consolidación y ampliación de líneas de investigación sobre feminismo y educación en contextos territoriales, teniendo como objetivo contribuir con propuestas teóricas, metodológicas y políticas del feminismo, amplificando su interrelación y aplicación con las prácticas locales y su sinergia con investigaciones con otros enfoques y epistemologías, tales como los estudios sobre mujeres, conflictos y paz, desarrollo humano, movimientos feministas, políticas públicas, juventudes, interculturalidad e interseccionalidad.

Los aportes del feminismo a la educación son herramientas que nos sirven para pensar y recuperar sentidos, prácticas vividas, cambios y construcción de conocimientos que convoquen a transformar y rechazar prácticas de subalternidad y exclusión. Nos sirve para hacer de nuestras prácticas, practicas reflexivas, críticas, cuestionadoras, irreverentes, indisciplinadas no solo en relación a los roles estereotipados de mujeres y hombres, sino para buscar claves para vivir en mundos mejores.

Aquí, tratamos de no repetir pautas desde otras claves, sino de hacer un aporte para cambiar nuestras concepciones de lo que es y para lo que sirve la educación. Tratamos a de-construir compartimientos estancos que separan la educación formal de aquellas informales o populares poniendo en contexto a las actrices y actores individuales y colectivos; buscamos rescatar nuestras existencias como personas con derechos e intereses, sexuadas a partir de historias vividas e historias narradas, historias co-construidas con otros. (Gargallo, Francesca: 2008)

La escuela en particular y la educación en todo ámbito social, son muy a menudo, instituciones de reproducción de las relaciones sociales establecidas, pero en otros, la educación es y puede ser un poderoso instrumento de transformación social. De nosotras - del feminismo como praxis - depende en gran medida, generar procesos lo suficientemente críticos y desestabilizadores para crear condiciones para otras relaciones de poder, de saber, de hacer... de nuevos escenarios posibles.

Las dificultades y necesidades de una educación feminista plantean dilemas, desafíos y contradicciones, implica centrarnos en la relevancia de incorporar o no el feminismo en la educación como una necesidad de política pública que no discutiremos aquí. Desde el feminismo, el propósito es abrir nuevos horizontes, ficciones y realidades que repercutan en toda la dimensión educativa. En uno u otro territorio de aprendizajes, algunas de las metas son provocar a los jóvenes e introducir dudas sobre la imagen que tienen de sí mismos, de las otrxs y de la 
sociedad a la que pertenecen.

El camino que trazan y transitan las mujeres desde situaciones de marginalidad y subordinación hacía situaciones de autonomía y con posibilidades potentes para intervenir en procesos de decisión colectivos los situamos en el marco de procesos educativos: es el potencial de ampliar capacidades que pueden generar confianza, autonomía, fortalecimiento y reconocimiento. La educación crea condiciones de posibilidad para el empoderamiento, lo que conlleva a dar contenido al concepto y a las condiciones de poder que son necesarias de instalar.

\section{UNA APROXIMACIÓN FEMINISTA QUE NOS PERMITA HACER (NOS) PREGUNTAS}

¿Cómo abordamos la exclusión, la inclusión y la diversidad como común denominador?; ¿cómo recuperamos las múltiples identidades y los itinerarios singulares?, ¿cómo facilitamos la generación y respetamos las expresiones culturales en torno a los roles genéricamente asignados a las mujeres y los hombres, los procesos organizativos que instalen otras nuevas propuestas colectivas y nuevos territorios comunes? ¿cómo impulsamos prácticas democráticas que consideren a los actores de la educación autores de sus prácticas? ¿cómo incidir reflexivamente e institucionalmente ante posiciones de docentes, estudiantes, comunidades sobre temas que niegan u ocultan - con gestos, omisiones, reproducción de estereotipos, actitudes sesgadas, miradas de aprobación o reprobación las desigualdades sociales, prácticas culturales hegemónicas, la raza, las lenguas, el sexo, la religión, el nivel de instrucción o la pertenencia a comunidades no hegemónicas y los conflictos de género en los espacios educativos/ espacios de vida? ¿Cómo contribuir a que una comunidad o territorio sea un espacio en construcción sino se cree y no se practican valores y competencias sociales tales como la solidaridad, la no violencia, el reconocimiento del otro, la cooperación, las relaciones equitativas entre los géneros?

El tratamiento de lo educativo lleva la huella de la diversidad; los dilemas entre cada corriente feminista sobre la educación lo informan. Entre otras cuestiones significativas re-situar la cuestión del cuidado - frente a la violencia, la exclusión, la ofensa, la indignidad, la soledad, la marginalización, el no cuidado de los derechos - implica 
atender su lugar diferencial en el mapa de posturas, tanto desde las pedagogía crítica y feministas; desde el construccionismo, y el paradigma de la complejidad, reconociendo la ambigüedad que denota el estado teórico de la educación: ¿es un modelo, una herramienta o un valor?

Chimamanda Ngozi Adichie (2017) es una escritora nigeriana comprometida con las luchas contra la discriminación hacia las mujeres y contra el racismo. En su libro, "Chère Ijeawele manifesto para una educación feminista”, responde a una amiga sobre cómo afrontar el nacimiento de su hija

\section{a. sé una persona plena y entera:}

no seas dura con vos misma. Pedí ayuda y contá con otras mujeres.

Date el permiso de equivocarte. No tienes que saber todo.

Date el tiempo que necesites para vos misma

Date la posibilidad de seguir con tu trabajo. No es incompatible

b. enséñale a tu hija que los roles de género no tienen sentido. «Porque eres una niña» nunca será una buena razón para nadie. Jamás.

Estamos tan profundamente condicionadas por los roles que los obedecemos, aunque contradigan nuestros verdaderos deseos, necesidades o nuestro bien estar. No hace falta disfrazar el poder que tenemos.

c. enséñale a cuestionar las palabras.

Las palabras son receptáculos de nuestras creencias, presupuestos, prejuicios. Nosotras podemos decidir que nos autorizamos (o no) a decir a nuestros hijos. Porque cada cosa que le decimos cuenta, es lo que les enseña el valor que le damos a las cosas, a la gente y a las ideas.

d. enséñale a no preocuparse por gustarle a los demás.

Ninguna niña debe buscar ser amable pero siempre debe ser plenamente ella misma, una persona sincera y consiente que es un ser humano como los otro.as

e. enséñale a ser sincera, que tenga coraje de expresarse.

Dile que ella no es un objeto que amamos o no, ella es también quién ama o no ama.

f. explícale sobre los privilegios y las desigualdades, sobre la ética del reconocimiento y la dignidad.

UNA APROXIMACIÓN FEMINISTA QUE PERMITA PROMOVER UNA 


\section{EDUCACIÓN DE LAS DIFERENCIAS}

¿quién no es diferente? De cerca, ¿hay alguien que sea igual a otra. o?

Históricamente, abordar las diversas dimensiones del problema de la equidad en la educación de América Latina, remite a prácticas sociales de exclusión, negación y aniquilamiento del otro diferente constituyendo identidades desde la deslegitimación y la negación. La escuela colaboró en ese proceso de reproducción de una única identidad común y con el argumento de una educación universal, promovió la eliminación de las diferencias, justificó clasificaciones, desvalorizando identidades que no se adaptaban al modelo propuesto e impuesto. (Fernández, 2008 y Freire, 1997). Los argumentos sobre el respeto y la comprensión, o más aún, la tolerancia de las diferencias esconden relaciones asimétricas y de exclusión desde "el prejuicio y la discriminación que no constituyen sólo un desvío o una patología individual, sino que dependen de categorías y clasificaciones que están profundamente inscriptas en la historia y en el tejido social", (Silva, 1997, p. 71) En este sentido, las relaciones que se dan en la escuela no son naturales ni neutrales, sino que son producto de constantes negociaciones de significados.

La escuela impone una "normalidad integradora" (Sinisi, 1999, p. 189) de las diferencias, con imágenes naturalizadas, y los alumnos ponen en juego variadas estrategias a fin de adecuar su imagen a las expectativas que circulan sobre ellos. La escuela no es neutra y tampoco los espacios de formación docente ya que son referentes directos construcciones identitarias ligadas a roles de género tradicionales. Es por esto que es un objetivo muy actual, el poder reflexionar sobre la formación de los formadores como punto de referencia para prácticas que permitan una educación igualitaria, teniendo en cuenta la enorme importancia que tiene el acceso y la permanencia de las niñas en el sistema educativo.

En las prácticas pedagógicas cotidianas, podemos distinguir al menos tres discursos en relación con las diferencias que remiten a distintos usos de las mismas. Uno de ellos, el discurso humanista de la igualdad, supone no cuestionar el modelo hegemónico cultural; la escuela funciona como transmisora de dicha hegemonía, y enuncia como obvia la igualdad de todas las personas por el solo hecho de pertenecer a la especie humana, proponiendo, en consecuencia, la tolerancia de las diferencias. Otro discurso denominado de la diferencia, se ubica en el otro extremo del péndulo, afirman la necesidad de sustentarse en las diferencias y cuestiona la posibilidad de proporcionar, desde un sistema hegemónico, los mecanismos generadores de igualdad. El último de los discursos es el de la relación 
diferencia-semejanza, que coloca el acento en esa relación, subrayando su construcción desde el poder y la afirmación de un término sobre otro. Este enfoque denuncia y asume que uno de esos polos ha ido ocupando el lugar de lo negado y excluido, construyéndose a sí mismo como subsidiario del otro polo, producido como dominante (Pérez de Lara, 1996).

Desde una relación dialógica, es decir, desde el encuentro entre seres humanos mediatizados por el mundo para pronunciarlo, la educación emancipadora favorece la reflexión sobre las relaciones con el mundo, poniendo en cuestión y problematizando la vida cotidiana del educando y el educador, lo que genera la inserción crítica en la realidad. Esto nos lleva a de-construir mandatos sobre un docente transmisor, generador de vínculos de dependencia entre dos personas, una que sabe y da y otra que no (Freire, 1997).

Desde este posicionamiento, proponemos una concepción de la educación como una invitación para una reflexión crítica, un desafío para plantear interrogantes, un aporte para pensar respuestas con otros y para sostener decisiones responsables (Pérez Aguirre et al., 2002, p. 87).

En ámbitos educativos, el encuentro con el otro abre un territorio de reflexión y toma de decisiones. Si bien los recorridos escolares están condicionados por diversos factores, no son invariablemente determinados por ellos, en estas prácticas hay oportunidades de construcción diferentes; es posible construir prácticas pedagógicas cotidianas que trabajen con, desde y en las diferencias sin que estas se transformen en desigualdades. Identificar las diferencias, no en relación con un grupo, sino en función de las particularidades de los sujetos, promueve una pedagogía de las diferencias desde la cual el otro es considerado como legítimo (Maturana,

Esto nos permite identificar prejuicios y obstáculos en el quehacer educativo ya que los otros (nos-otros) pueden aportar mucho más que un mandato estereotipado, constituyéndose en oportunidad, construir sentidos diferentes a los naturalizados, guiados por la convicción de que la transformación es posible.

La educación para la humanización propuesta por Paulo Freire invita a dejar de estar siendo para otros, dejar de ser objetos de, para reconocer, reconocerse y reconocernos como sujetos protagonistas.

¿Transformarse para transformar el mundo o cambiar el mundo para transformarnos? $O$ ¿ambas acciones al mismo tiempo? Desde un pensamiento no binario, multidimensional, insistimos en las emergencias, los lazos, las simultaneidades más que en las separaciones, explicaciones o secuencias.

EL FEMINISMO Y LA INTERCULTURALIDAD SON ENFOQUES FACILITAN

Momento: diálogos em educação, E-ISSN 2316-3100, v. 28, n. 3, p. 154-177, set./dez, 2018. 


\section{UNA EDUCACIÓN PARA EL RECONOCIMIENTO Y LA SONORIDAD:}

Entendemos la educación como un proceso complejo que contribuya a pensar e intervenir; es una propuesta abierta al diálogo con distintas miradas que apuntan a pensar, crítica y auto-críticamente. Partimos de teorías dialógicas que proporcionan nuevos elementos para la co-reflexión y la acción desde el (re)conocimiento de cada realidad social.

Anclando en perspectivas epistémicas de los paradigmas feministas y de la complejidad; portando miradas curiosas, inéditas, inesperadas, voces insospechadas, divergentes, contrapuestas, escenarios generativos que es posible potenciar diálogos que posibiliten enlaces en contextos sociales que se co-construyen; creando condiciones de posibilidad desde y hacia prácticas reflexivas.

Son diferentes lentes los que podemos usar; precarios, transitorios pero que permiten enfocar nuestras miradas como investigadores, activistas, co-guionistas de historias en curso. Sin certezas ni regularidades; aportando a una construcción social y cultural de las realidades que co-construimos, estos son algunos de los desafíos que nos permitirán construir conocimientos y no necesariamente verificar teorías.

El conocimiento no es nunca un proceso abstracto - y mucho menos un producto -. Es algo que ocurre en el espacio "entre": entre un sujeto y sí mismo, en su interacción con otros en contextos singulares.

\section{EL FEMINISMO APORTA LA NECESIDAD DE HABLAR CON OTRA. OS: LOS DIÁLOGOS PÚBLICOS}

Los diálogos son prácticas educativas que permitan entusiasmar a los protagonistas del tejido social, En la vida cotidiana la gente conversa, se cuenta historias, intercambia información, pero los diálogos públicos que planteamos como procesos comunicacionales trascienden las acciones típicas de la simple charla. Al diálogo público que nos referimos, no surge espontáneamente, sino que es una conversación provocada, tiene la intención de que los participantes se involucren, de que puedan ser protagonistas de un proceso de comprensión, con el objetivo de hallar nuevos significados. El termino público no implica que esas conversaciones deban realizare con muchas personas, son los temas que se tratan los que son de interés público y esto lo que le da su especificidad, si bien es básico poder trabajarlo desde las 
historias y trayectorias personales.

Esto es así porque cuando contamos la historia desde nuestras propias experiencias estamos construyendo una narrativa que constituirá una historia verdadera. Pequeñas grandes historias que nos distinguen, diferencian sostienen e incluyen en un mundo que compartimos con otros. Dialogar nos posibilita recrear historias que afectan a las personas, las relaciones y los mensajes.

Los discursos fuertes, dominantes, normativizados, machistas, patriarcales; influyen en las ideas, experiencias, observaciones que se juzgan normales o no, relevantes o no. tienen la capacidad de amplificar, legitimar, convalidad experiencias y relatos, así como de desacreditar e invalidar otras. Quizás por esto nuestro trabajo busca alentar la participación de aquellos cuya voz es marginada de esos discursos. Además, cuando son pocas las oportunidades de intercambio, se tiende a simplificar cualquier elucidación del otro; las propias descripciones y explicaciones son pocas veces cuestionadas; se hacen menos excepciones. (Becker, 2000) El problema no estaría centrado en que las personas tengan prejuicios (porque son rígidos, no entienden o son intolerantes...) sino que, "en tanto y en cuanto continuamos con el proceso normal de generar consenso en torno a qué es real y a qué es bueno, se organizan categorías de las cosas indeseables" (Gergen K)

"Tener conciencia de mi humanidad consiste en darme cuenta de que, pese a todas las muy reales diferencias entre los individuos, estoy también en cierto modo dentro de cada uno de mis semejantes". (Savater, 2011)

En un contexto democrático es sustancial poder aprender a asumir nuestra fragilidad y la necesidad de un protagonismo activo, compartido, ciudadano. Es en este contexto, que los diálogos plantean el reconocimiento de las diferencias, la comprensión como modo de reconocer lo que el otro siente, el tratar de entender su forma de vivir y de comportarse (aunque sea muy distinta a la nuestra), partir de la certeza de que cada uno, con otros, puede ser protagonista responsable de lo que hace y de las consecuencias de su accionar.

Gergen K, (2000) propone distinguir el diálogo transformador como "cualquier tipo de intercambio que logra transformar una relación entre individuos comprometidos con realidades diferentes y antagónicas (y con sus prácticas conexas), en una relación en la que puedan construirse realidades comunes y consolidadas".

Desde este concepto, son prácticas que anudan y que enredan: que buscan 
transformar, entrando y saliendo de las conversaciones que se suscitan, generando otras, agregando palabras, reconociendo emociones, compartiendo opciones, negociando significados. Pueden durar algunas horas o unos pocos días, provocan entusiasmos, dudas, permisos, asombros, preguntas, presiones, deseos, libertades, ideas, encuentros.

Cuando contamos la historia de una experiencia estamos construyendo las verdaderas historias. Las verdaderas historias son esas pequeñas-grandes historias que los humanos vivimos, escribimos, narramos, escuchamos, recordamos, son esas historias las que nos sostienen, diferencian, nos incluyen como personas.

Cuando la gente participa se producen cambios. El poder hablar y escuchar, conversar, hace más permeable, más accesible, más cercano el mundo a la gente y el mundo de la gente. Un grupo de diálogo es un grupo de gente que conversa, que comparte experiencias, discute, negocia sentidos y significados. Las relaciones se forjan en esa mezcla de voces entre historias privadas y públicas, todas atravesadas por posturas - convicciones - conflictos que cada uno tiene consigo mismo, con otras visiones, creencias, intereses, necesidades, valores.

Los diálogos facilitan tiempos y lugares para contar historias: son espacios en donde se desarrollan procesos de interacción, de co-construcción, de intercambio y de modificación de las diferentes realidades cotidianas. Es una posibilidad para que mucha. os puedan compartir con otra. os sus ideas, porque cada palabra, cada historia es válida y es importante para poder ir reconociendo y construyendo otras historias, con los otros. Se crean o visibilizan espacios públicos en donde se construyen procesos que facilitan la búsqueda alternativa de respuestas (aún pequeñas, transitorias o parciales), al mismo tiempo que permiten aprehender nuestras realidades de manera diferente.

En tiempos en donde todo parece igual, ¿Cómo reconocer las semejanzas y las diferencias? ¿Cómo escucharlas y entenderlas? Dialogando nos introducimos en un proceso educativo que permite negociar significados, sentidos, conversaciones que llevan a la construcción de culturas ciudadanas inclusoras. Pasa por reconocer y conocer, criticar y respetar, encontrar herramientas para cuestionar y generar opciones alternativas. Pasa por la posibilidad de que cada uno pueda ser autónomo, protagonista y responsable de lo que dice o no, de lo que hace o deja de hacer, pasa porque cada uno pueda involucrarse. Schaffer (2000) pregunta

¿por qué narrar, contar, conversar? Porque contar historias 
de nuestras vidas ayuda a comprender el significado de las dificultades y de los problemas. Para que el cambio se torne creíble y alcanzable"

Desde esta perspectiva, un diálogo, a diferencia de un debate no busca generar modificaciones generales: propone conversar como un trabajo que nos damos para encontrar a otros, apoyándonos en las experiencias de cada uno. Conversaciones que nos permitan construir culturas múltiples mientras cambiamos algunos argumentos y relatos del guión de esas, nuestras historias de carne, hueso y corazón. Dialogar no se refiere a la conversación entre dos actores sino "a través de" (Bohm, 1996). Son la cocreación de significados a través de y entre distintos interlocutores, permite encontrar espacios intermedios y perspectivas emergentes que puedan ser apropiadas por los participantes, concibiendo a futuro realidades posibles que necesitan conformar (Schnitman, 2000).

¿Para que un Diálogo Público? En todo diálogo subyace la noción de reconocimiento de las diferencias, de conflicto como oportunidad y de escenarios de encuentro que permiten la construcción de nuevos conocimientos. Así, desde nuestras experiencias de intervención, de investigación, de investigaciónacción las utilizamos como dispositivos que permiten promover conversaciones que giran en torno al involucramiento personal, posiciones que se ven re-visadas y revisitadas en el marco de una inter-acción y un entre-cruzamiento desde distintas miradas, trayectorias, perspectivas. Es lo que venimos realizando desde hace varios años: provocamos y creamos tiempos y espacios conversacionales en comunidades y con organizaciones, facilitamos herramientas para hacer diagnósticos o evaluaciones participativos y planificación cooperativa. Implica acompañar procesos organizativos o de fortalecimiento de las organizaciones; muchas veces buscando destrabar situaciones conflictivas otras, se plantean temas controversiales que buscan abrir posturas, posiciones, perspectivas sin necesidad de síntesis ni de consensos. Lo que subyace a estas estrategias es la oportunidad de construir escenarios conversacionales generativos. Escenarios que podrán ser, pero que aún no son.

"Si es preciso compartir significados y verdades, tenemos que hacer algo distinto" David Bohm (1996)

\section{LAS CONVERSACIONES DESDE EL CONSTRUCCIONISMO SOCIAL Y}




\section{LA COMUNICACIÓN}

"Nuestras teorías a menudo son mecanismos más eficientes de encierro, orden y control social que los regímenes sociales, políticos o estéticos que ellas investigan" afirma (Wigley, 1995).

Al tener como objetivo en nuestras intervenciones, construir y recoger conocimientos significativos, socialmente útiles, situados en los contextos y trayectorias de los actores involucrados en esos procesos, necesitamos pensar distintos modos de representar y construir mundos y conocimientos sobre él. Superar el modelo lineal monológico que habilitan los modelos de indagación e intervención que usualmente aplicamos. Implica de - construir/re-construir: La deconstrucción no se ocupa de lo nuevo sino de lo viejo, de lo conocido, de lo familiar. Es repensar el cotidiano que de tan familiar está casi invisibilizado, descubriendo en esas familiaridades, cualidades cruciales inesperadas imprevisible y que, por eso, desvían o comprometen la escena en que se encuentran (Wigley, 1995)

Muchos de estos modelos se encuadran en una concepción de la comunicación como reflejo y acumulación de información y tendemos a tratar la comunicación de $2^{\circ}$ orden como productora de sentido y de realidades desde los denominados paradigmas de la complejidad. Estos consisten en otras maneras de pensar sobre nosotros, sobre nuestras relaciones y los contextos, territorios, lugares que ocupamos y co-construimos.

En el denominado paradigma de la simplicidad, se suponía que el lenguaje se refiere al mundo. Lo representa, habla de las cosas que están "afuera". Plantea la transmisión de mensajes como función central de la comunicación y se define como un proceso secundario. Superando este modelo, se comenzó a visibilizar que la comunicación implica otros elementos, Warnett Pearce (1995) vincula cuatro características: (1) el lenguaje no representa al mundo, lo construye. "Decir cómo se llama algo no es simplemente nombrarlo o hablar sobre eso: es, en un sentido muy real, convocarlo a ser como uno lo ha nombrado" (2) la función primaria del lenguaje es la construcción de mundos humanos y no simplemente la transmisión de mensajes de un lugar a otro. “...la comunicación retorna así un proceso constructivo, no un mero carril conductor de mensajes e ideas..." (3) la comunicación es un proceso social primario (4) vivimos inmersos en actividades sociales, y el lenguaje está en nuestros mundos, pero no es el parámetro de estos; impregna esa totalidad, pero no es la totalidad". 
a la que hemos sido invitados pero llegamos tarde (Kenneth Burke²)

Este enfoque del construccionismo social plantea (1) que el mundo social consiste en actividades. En este caso, esas actividades son las conversaciones que entablamos en conjunto. (2) la capacidad que tenemos los humanos de hacernos un lugar en esas conversaciones que habitamos, las que nos permiten descubrir nuestras identidades, conocimientos, valores mientras nos desplazamos en ellas. (3) existen reglas de lo que debemos o no hacer. ¿Cómo actuar, que decir, que esperar? ¿cómo me responderán? ¿Su respuesta me servirá? Dice Pearce (op.cit): “nos movemos en ida y vuelta entre los relatos que contamos, es decir, como entendemos los aspectos mentales, cognitivos o verbales de nuestras vidas y los relatos que vivimos - los aspectos físicos de nuestras vidas en que interactuamos con otra gente. (4) El núcleo de nuestros mundos sociales está conformado por nuestro hacer. Todo lo que hacemos es co-construido, no realizar algo sin estar en interacción con otros.

Esto se puede explicar cómo lo hace Schotter: Cuando alguien te pregunta ¿qué quieres decir con esto? refiriéndose a algo que acabas de decir, la respuesta apropiada sería "todavía no lo sé, aún notemos terminado nuestra conversación"

Se trata de reformular y generar otras nuevas preguntas, de recuperar lenguajes, de hacer (nos) preguntas y buscar respuestas en voz alta para que todos puedan (podamos) escucharnos y responder.

Las perspectivas feministas e interculturales son troncos conceptuales que se entrelazan entre sí y con metodologías que puedan contribuir a un paradigma superador de la educación que aporten nuevas preguntas y alternativas, en todos los casos, privilegiando la calidad de las interacciones que se producen (Laroussi et al, 1995)

¿Por qué la educación debe tratar sobre la singularidad, la alteridad, de una educación que debería poder dar respuestas singulares?

¿cómo tener en cuenta hechos de historias únicas, casi anécdotas que pasaron en la vida de cada una. o, y que muchas veces "marcan" como somos, como vamos siendo...? ¿cuáles son las prácticas que dan lugar a las diferencias y cuáles las obstruyen?; ¿qué lugar ocupa el otro en los espacios educativos?, ¿cómo se instalan los conceptos de normal o anormal? ¿qué pueden hacer los distintos actores de los procesos para que la educación posibilite a cada una. o a ser otra. os y hacer otras cosas de lo que ya somos y hacemos? ¿Qué recorridos, por qué caminos, desde qué

${ }^{2}$ Burke, K., The Philosophy of Literary Forms, N Y. Vintage Books. 1957 citado por Pearce Momento: diálogos em educação, E-ISSN 2316-3100, v. 28, n. 3, p. 154-177, set./dez, 2018. 
itinerarios, con que narrativas se presupone incluir, convivir, tolerar, comprender, aceptar? ¿Qué cambios se pueden generar desde el seno de las organizaciones e instituciones estatales o comunitarias? ¿Cómo se negocian las diferencias? ¿cómo se gestionan y transforman los conflictos?

Es en los escenarios que se producen encuentros y desencuentros, conflictos y emociones, dudas, afectos, cuidados y descuidos hacía el otro. Es allí donde reside lo singular, la alteridad, la diversidad, la capacidad de recuperar experiencias y re-crear nuevos saberes, la necesidad de relaciones entre-nosotras. os/ con-nos-otra.os.

Slikar (2008) sugiere que plantea, por un lado, el problema acerca de la idea de inclusión y de con-vivencia; por el otro, la dimensión esencialmente vincular de los procesos pedagógicos, por último, un cambio de preguntas: de ¿Qué pasa con la inclusión? a: ¿Qué nos pasa con la inclusión? Esto es un cambio de perspectiva en la conversación, ya que quiere saber acerca de nuestra experiencia y nuestra relación con esto, se abre a una escucha intima, busca saber qué interpela, qué reflexiones y comportamientos provoca. Las cuestiones planteadas - agrega Slikar - se valoran en las conversaciones en donde surgen representaciones de inclusión, diversidad, diferencia, solidaridad, sonoridad, convivencia... y con diferentes formas de concebir la inclusión a distintas puertas que remiten a experiencias diferentes: la de las instituciones que tienen abiertas sus puertas y que no piden n ni exigen nada del que llega (b) la de las instituciones que dejan entrar a algunos y que, por eso, excluyen, expulsan a otros.

\section{UNA EDUCACIÓN FEMINISTA Y POPULAR}

La educación popular asociada con las causas de las mujeres y con la construcción de otros mundo posible desde el feminismo empieza a dibujarse más, como producto de las teorías feministas. Torres (2003) plantea que corrientes consistentes en su opción política de transformación, aspiran a una educación popular feminista en lo personal y colectivo.

La educación popular es sustantivamente política, feminista y pedagógica, comunicativa e investigativa. Entendiendo la metodología como el proceso sistemático e intencionado de producción de conocimiento colectivo, aspiramos a una educación popular feminista que sustente en la pedagogía la afirmación de que las personas conocemos todo el tiempo y con todo el cuerpo. No sólo con la mente y con la racionalidad.

Requerimos de una educación popular feminista que traduzca en una apuesta metodológica y pedagógica el principio feminista de que lo personal es político y desde 
ahí, coloque la reflexión desde lo personal y de las subjetividades no como puntos de partida, sino como parte del recorrido.

La subjetividad es la experiencia personal del mundo que tiene cada persona. La subjetividad no es lo individual e íntimo. Su potencia deriva precisamente de que es lo que conecta a cada persona con el mundo, con la sociedad, con la familia, con la naturaleza, con las organizaciones.

El abordaje desde las emociones y desde la subjetividad es intencional. Respeta un posicionamiento metodológico, pero también político, en tanto busca recuperar y validar dos de las formas de conocimiento de las mujeres más devaluadas en nuestras sociedades patriarcales.

\section{APORTES PARA UNA EDUCACIÓN DESDE UNA PERSPECTIVA INDISCIPLINADA}

Alicia Stolkiner (1987) plantea que de ".. la interdisciplina nace la incontrolable indisciplina de los problemas que se nos presentan actualmente. De la dificultad de encasillarlos. Los problemas no se presentan como objetos, sino como demandas complejas y difusas que dan lugar a prácticas sociales inervadas de contradicciones, imbricadas con cuerpos conceptuales diversos".

Los nuevos conceptos y categorizaciones sólo surgen de nuevos modos de experimentar y construir significados. Sólo la diferencia puede producir diferencia. La novedad sólo nace de un encuentro con otro.

La autora afirma que en la actualidad estamos asistiendo a "un movimiento que va de la ciencia poseedora de un objeto y un método, a campos conceptuales articulados en prácticas sociales alrededor de situaciones problemáticas".

\section{UNA PEDAGOGÍA QUE RECUPERA LA IMPORTANCIA DE DISPONER DE SILENCIOS}

Un hallazgo significativo durante nuestros trabajos con mujeres rurales fue aprender sobre la necesidad de reconocer sus silencios como posturas y como respuestas. Fue cuestión de respetarlas y tratar - pacientemente - de interpretar. En una ciudad fronteriza de Bolivia como es Yacuiba ${ }^{3}$, ruidosa - con sus mercados, ferias, el centro, las

\footnotetext{
${ }^{3}$ Yacuiba es parte del conglomerado urbano conformado con Pocitos en Bolivia y Salvador Mazza (en Salta, Argentina)
} 
plazas, las esquinas, los trufis ${ }^{4}$, colectivos, lugares de trabajo - había lugares para conversaciones-aprendizajes donde relucían los silencios. Silencios llenos de matices, de miradas, de actitudes.

Xavier Albó (2013) aclara que en quechua s ch`in significa silencio y silencioso, ama chinea quiere decir "no callar". Este autor indica que en las culturas quechua y aymara se hace referencia al menos a tres tipos de silencio: (a) es el que se "oye" en una planicie o entre montañas, o en una casa campesina sin luz, teléfono ni agua caliente, o en un templo vacío: Ch'in pacha. "Es ese silencio, denso y que resuena, ese que ayuda a encontrarse consigo mismo, con el Cosmos, con el Dios Padre Madre, o como cada persona y cultura llame a lo que dé el sentido más profundo a su existencia”; (b) es el ama ch'inya, que se entiende como "no enmudecer cuando hay algo importante que decir"; es la versión quechua de frases más gramaticalizadas ama ch ’inyakuychu, y en aymara, jan amukt'amti: "no te calles". Puede ser un silencio cómplice del que, sabiendo, no avisa de algo grave: sin formalmente mentir, miente al ocultar parcialmente su verdad, la distorsiona, encubre, tapa evidencias. Así, el ama ch 'inya complementa el ama llulla. ${ }^{5}$ (c) Finalmente, está la modalidad ama ch'inyachinachu: "no hay que acallar a otros" (Albó, 2013).

Cada una de estas expresiones del silencio irrumpe y circula en los encuentros con mujeres en Yacuiba, como un modo de hacerse oír. Potencial que aún no exploran en toda su dimensión:

No pueden quedar silenciados tantos atropellos. Cuando denunciamos, ¿quién nos escucha? Es vieja y son larga nuestras luchas... parece que les pasa de costado... tiene que ser conocida, escuchada y (nosotras), valoradas. Saben que tienen mucho que aprender de nosotras (Olga. Suarez., Yacuiba)

Lo anterior se complementa con la referencia de Najmanovich (2007) a tres "figuras del silencio": la que adopta las formas del ocultamiento, la omisión, el secreto, la ausencia; el sutil silencio de lo impensable, aquel silencio íntimo que no se relaciona con lo oculto, ni con lo que se niega, sino que se vincula con lo que está más allá del lenguaje, que no pudo aparecer en el decir, pero que está, produciendo efectos, entretejiendo sentidos, un silencio que se manifiesta desde la ausencia; y el que posibilita pensar, silencio creativo que provee espacios para que aparezca algo nuevo en el discurso, para que brote lo que no estaba aún conformado.

\footnotetext{
${ }^{4}$ Se llama Trufis a los taxis colectivos.

${ }^{5}$ De origen quechua, quiere decir mentiroso, tramposo.
} 


\section{UNA PEDAGOGÍA QUE ANIME A REÍR}

Las mujeres con las que trabajo son, en general, desenvueltas y comunicativas cuando hablan sobre ser mujeres, sobre su percepción de la sexualidad, de los problemas que cargan, de las soluciones que intentan y de la vida en sí. Con frecuencia, reconstruyen sus vivencias y significados con energía, alegría, entusiasmo, asombro y hasta humor. Se miran, narran, se ríen, y se ríen de sí mismas, de actitudes y dolores superados. En contraste, en las entrevistas realizadas a hombres de las comunidades y funcionarios, estos hacen planteos con seriedad, poniendo distancias, con poco o ningún sentido del humor.

(...) sugiero una campaña: no arremeter contra las costumbres con la espada flamígera de la indignación ni con el tembloroso lamento del llanto, sino poner en evidencia lo que tienen de ridículas, de obsoletas, de cursis y de imbéciles (...) Les aseguro que tenemos un material inagotable para la risa (...) ¡necesitamos tanto reír, porque la risa es la forma más inmediata de la liberación de lo que nos oprime, del distanciamiento de lo que nos aprisiona! (Castellanos, 1995, p. 67).

Consuelo Martínez Lozano (2010:138) pregunta: ¿Por qué ellos son tan escuetos y serios, mientras ellas tan expansivas? y propone una posible explicación de género: las mujeres son educadas para expresar sus sentimientos, con la risa que embellece, el llanto que conmueve; están entrenadas para manifestar sus emociones públicamente (con excepción del enojo, la indignación o la abierta rebeldía, expresiones que "afean" o deterioran la "femineidad"). En cambio, a los varones se les asigna una permanente prohibición de expresar sentimientos porque esto los “afeminiza", así, hay un mandato de no exponer sus emociones: estas deben ser mesuradas, contenidas, y si es posible, inexistentes.

Desde esta perspectiva esta capacidad de exteriorizar emociones, aunque sea cierto que son parcialmente producto de roles culturalmente impuestos, se presentan como una oportunidad y una consecuencia secundaria magnífica, portentosa y poderosa.

"Al confesar nuestra subjetividad, nuestras debilidades $e$ incertidumbres, sabemos que nos hallamos más cerca de la objetividad que quienes creen que sus palabras reflejan el orden de las cosas" (Edgar Morín) 


\section{DUDAR Y CONSTRUIR}

Nuestras prácticas de investigación e intervención nos posibilitaron dudar y buscar metodologías que puedan ayudarnos a superar o completar la construcción de conocimientos parcializados, compartimentados, dividido por miradas disciplinadas y disciplinarias que nos entrenan en un saber ciego, sesgado y reduccionista.

Desestabilizar certezas y objetivar la atracción que produce estar y posibilitar vínculos nuevos nos lleva a repasar como trabajar para crear condiciones de posibilidad para que los sujetos (sujetados) puedan ser actores (autores) en realidades múltiples, multifacéticas, multidimensionales, complejas, de la que emergen construcciones de conocimientos nuevos, indisociables, saberes y prácticas articuladas, mezcladas, no aisladas (Morín, 1997)

Esto tiene significativas consecuencias: por un lado, nuestras maneras de mirar los mundos que habitamos y ubicarnos como actores desde nuestras múltiples pertenencias; por el otro, las derivaciones al momento de elegir y decidir nuestras intervenciones

Dos elementos: (1): el movimiento de ida y vuelta de la información favorece la emergencia continua de un nuevo contexto común, en cuyo caso el diálogo puede servir, no sólo para hacer comunes ciertas ideas o ítems de información que ya son conocidos, sino también para hacer algo en común, es decir, para crear conjuntamente algo nuevo (David Bohm, 2001), (2) los diálogos trabajan con una "lógica" de posibilidad (y no de verdad) que expande la creación de posibilidades a límites insospechados.

La perspectiva generativa en el diálogo es un proceso gradual de creación de posibilidades, de relaciones, perspectivas, competencias, etc.) entre personas o grupos mediante el diálogo, la reflexión y el aprendizaje. Así, para que un diálogo tenga un poder generativo es necesario que los procedimientos incluyan: innovaciones mediante la vinculación de diferentes temas, el desarrollo de nuevos temas mediante la transformación de comentarios en temas centrales, el descubrimiento de lo novedoso en lo que acontece, lo actuado, lo dicho o escuchado, el reconocimiento de recursos y valores, la introducción de visiones de futuro y la reafirmación de las personas como productoras de conocimientos y prácticas, la formulación de nuevos significados, argumentos inéditos y modos de narrar una situación. Hay algunas herramientas básicas para posibilitar esos componentes generativos de un diálogo; estas son las preguntas, el cambio en las narrativas, las metáforas, las invitaciones, las exploraciones. 
La comunicación no es un vehículo para la transmisión de información sino un proceso constructivo: cada expresión en un diálogo es un enlace en una red de otros diálogos, al mismo tiempo posibilitada y limitada por enlaces previos y futuros. Los enlaces se obstruyen y resuenan con lo que se habló en el pasado creando posibilidades novedosas $^{1}$ (Bakhtin, M.,1986)

Un espacio generativo es un espacio en construcción comunicacional y de aprendizaje ya que implica sostener experiencias de construcción colectiva, favoreciendo y promoviendo el intercambio dialógico entre las distintas narrativas; descubriendo lo novedoso en lo usual; favoreciendo la emergencia de saberes implícitos e invisibilizados de los involucrados; activando contextos de innovación y re-visitando de un modo constante y crítico lo con-versado.

\title{
EL COLECTIVO DE MUJERES CHAQUEÑAS ${ }^{6}$ UNA RED DE RECONOCIMIENTO Y COLABORACIÓN
}

Es un espacio en red que se constituye como un territorio de construcción continúa de aprendizajes, lo que permite con luces y sobras ampliar y consolidar procesos de los grupos de base territoriales de las mujeres. En su visión el Colectivo plantea:

\begin{abstract}
“... Nos reconocemos como una comunidad en continuo proceso de aprendizaje, con un proyecto compartido de acción, de incidencia, con mecanismos que incluyan el diálogo, la deliberación, la colaboración y el respeto, sin excluir perspectivas diversas, críticas, disensos y conflictos. "
\end{abstract}

Esto revela su marca distintiva su heterogeneidad y la valoración de nuestras diferencias. Del conjunto de mujeres, las diferencias son su característica básica: se distinguen, pero no se enfrentan las trabajadoras urbanas, las campesinas, las blancas, las mestizas, las indígenas, las profesionales, las intelectuales, las funcionarias, las jóvenes, las viejas, las abogadas y las curanderas, las estudiantes y las empleadas, etc. Los límites identitarios inestables e inseguros; las disputas por el poder y los conflictos ideológicos y de intereses, están puestos sobre la mesa. Estas mujeres que se saben

\footnotetext{
${ }^{6}$ El Chaco americano es una ecorregión de gran diversidad ambiental, social, cultural y política, con modelos sociales contrapuestos y generadores de disputas que abarca 3 departamentos en Bolivia, 3 en Paraguay, 13 provincias en Argentina y un estado en Brasil. Es considerada una unidad ambiental y la segunda región boscosa más extensa de América del Sur después de la selva amazónica. Sus límites naturales no coinciden con los límites políticos, así como sus componentes naturales y culturales son compartidos más allá de las fronteras nacionales.

${ }^{7}$ Documento de referencia del Colectivo de Mujeres del Chaco Americano (2012)
} 
distintas entre sí, no vislumbran al colectivo como un dispositivo de vanguardia que despierta conciencias; no viven realidades fijas en contextos estables, ni esperan que sus realidades sean reveladas para luego cambiarlas. Se saben parte de una realidad que se re-crea mediante la práctica y en el seno de las conversaciones.

La diversidad, como marca distintiva, se relaciona con la identidad, en tanto producto de la demarcación de diferencias y de exclusiones, se constituye a partir y a través de las diferencias y no al margen de ella, no se manifiestan como señales de unidades naturalmente conformadas. A lo largo de sus recorridos, sus adhesiones identitarias funcionan como puntos de identificación y adhesión por su capacidad de excluir, omitir, dejar afuera. Históricamente, las identidades se tornan cada vez más posicionales, políticas, plurales y diversas; menos fijas y unificadas. Son identidades situadas en un tiempo particular, fragmentadas a partir de la multiplicación y diversificación de las pertenencias sociales; de la ausencia de una representación unificada de la propia identidad y por el carácter provisional de las pertenencias.

El espiral como metáfora de movimiento, marca ciclos que inician y terminan para volver a empezar. Un espiral significa una línea que describe un trayecto en círculos concéntricos ascendentes o descendentes, según el punto de inicio. Es una curva que da indefinidamente vueltas alrededor de un punto, alejándose de él más en cada una de ellas. También se usa para indicar una sucesión creciente de acontecimientos (espiral de acontecimientos, de cambios, de conflictos, de violencia, de cambios, de optimismo). Cuando las mujeres comienzan a contar sus historias, desde las jóvenes hasta las más viejas, despliegan sus vidas como si fuera ese espiral, convirtiendo las historias sobre sus trayectorias en una oportunidad de ubicarse desde distintos lugares, de los que recuperan nuevas e inesperadas perspectivas ya que miran y se saben vistas, desde otros lugares. Lo que las tranquilizaba en estos relatos en espiral es poder re-volver al punto anterior.

\section{A MODO DE CONCLUSIÓN: LA EDUCACIÓN COMO HERRAMIENTA DE FORTALECIMIENTO E INCIDENCIA}

\section{La oportunidad de cambiar}

Mariposa se dice panambí en guaraní

Para que la oruga se convierta en mariposa debe encerrarse en una crisálida. su sistema inmunitario comienza a destruir todo lo que corresponde a la oruga, incluido el sistema digestivo, ya que la mariposa no comerá los mismos alimentos que la oruga. Lo único que se mantiene 
es el sistema nervioso... Así, la oruga se destruye para poder ser mariposa; cuando rompe la crisálida, aparece inmóvil, con las alas pegadas, incapaz de desplegarlas...; y de pronto, la mariposa comienza a volar (E. Morín, 1995)

Educar es una invitación para entablar nuevas conversaciones: significar, elegir, interpretar, preguntar y repreguntar; permitiendo comprender y explicar. Aprender no es algo natural, incluye rupturas, cuestionamientos, revisiones del pensamiento y el actuar. Implica superar el paradigma en el que el saber es poder, es acumular datos e información, pero sin dar cuenta de quienes viven ese proceso; en donde la subjetividad, el error, lo distinto, las emociones, las pasiones, lo diferente debe ser dominado y los sujetos, objetivos: sin reconocer que pueden ser sujetas sujetadas u objetos de otros sujetos.

"Todas las cosas son ayudadas y ayudantes, mediatas e inmediatas, están ligadas entre sí por un lazo que las conecta, aún las más alejadas" (Pascal citado por E. Morin 1995)

Propongo otros modos de pensar la educación - multivocales y dialógicos - que van de la metáfora del lenguaje como espejo de la realidad a la metáfora de red. En donde las personas sean parte de múltiples redes de interacción, co-protagonistas de encuentros y diferencias. Desde allí podrán emerger otros términos: co-evolución, diversidad, organización compleja, auto-co-organización, conflictos, incertidumbre, desorden, preguntas. El conocimiento expresa las formas que adquieren las relaciones, es producto de la interacción con otros, con la realidad y está mediatizada por la cultura. Significa trazar y compartir mapas de rutas de acción y de pensamiento, buscando más allá de lo obvio; y concibiendo así a la educación como un proceso continuo de revisión, transformación y construcción, de negociación de significados, sentidos y conocimientos. Implicando aprehender estrategias - pensar, comprender, dudar, revisar, interpretar, optar, disentir y evaluar sus efectos-que posibiliten legitimar opciones.

Esto contiene un lenguaje estratégico, que permite elaborar respuestas a desafíos y resolver problemas. El lenguaje como recurso para co-construir con otros, identidades personales y sociales, incorporando las conversaciones como dispositivos; creando condiciones de posibilidad para un protagonismo responsable en contextos que determinan pero que pueden ser transformados. Su fuerza está en tener en cuenta las diferencias como oportunidad y posibilidad para crear significados, narrar y modificar historias personales, colectivas, públicas y privadas. Para re-volver y re-mover historias que permiten comprender, dar sentido y generar posibilidades de cambio. 
"Que los actos, gestos, discursos que parecian obvios se tornen problemáticos, peligrosos, dificiles" (Foucault)

El Colectivo de Mujeres - como una red que forma parte de otras redes locales y regionales - puede ser un territorio de mujeres que aprenden, un proyecto de acción, reflexión y colaboración. Para lograrlo deberán fortalecer su capacidad de comprender e interpretar los procesos que tienen lugar en su seno, responder demandas de otros y definir su propia agenda, recuperando historias, revisando problemas a partir de la identificación de lo que les preocupa, cuestiones en juego y desafíos.

Es un escenario para un guión que aún no se termina de escribir: su historia tiene un pasado que podemos interpretar, un presente que se construye y eventuales e inesperados futuros.

"Si es preciso compartir significados y verdades, Tenemos que hacer algo distinto" (David Bohm 2001)

Espero que las lecturas de la realidad y las propuestas que realizamos en este trabajo puedan contribuir a que el colectivo sea una organización de mujeres, socialmente presente, que decide sus caminos reflexivamente - molestando, provocando, dudando -; que sean espacios para que sus participantes se encuentren y fortalezcan. Que les sirvan para conocer, comprender y ejercer sus derechos con energía, sabiduría y libertad.

\section{REFERENCIA}

Albó, X. (2013). Boletín Virtual No 482, Año 12 Cipca-Bolivia. Recuperado de: www.cipca.org.bo.

Albó, X. (2013). Diario La Razón del día 6/1/2013. Bolivia. Recuperado de: http://www.la-razon.com/index.php?_url=/opinion/columnistas/Transparencia-II-Amachinya_0_1755424549.html.

Bakhtin, M. (1986). Speech Genres and Other Late Essays. Austin: U. of Texas Press.

Becker, C, Chasin L, Chasin, R, Herzig, M, Roth, S. (2000). Del debate estancado a una nueva conversación sobre los temas controvertidos: El Proyecto de Conversaciones Públicas en Resolución de conflictos: Nuevos diseños, nuevos contextos, D. Schnitman (comp), pp.155-178.

Bohm, D. (2001). Sobre el diálogo. Barcelona: Kairós.

Chimamanda Ngozi Adichie. (2017). Querida Ijeawele. Cómo educar en el feminismo. 
Ed. Alfred Knopf USA.

Derrida, J. (2001). De la hospitalidad. Buenos Aires: Ediciones de la Flor.

Derrida, J.. (2007). Aprender (por fin) a vivir. Buenos Aires: Amorrortu Editores.

Fernández, M. (2008). Hacia una pedagogía de las diferencias des de los aportes de la propuesta de Paulo Freire. In P. Freire. Contribuciones para la pedagogía. M. Godotti, M. V. Gómez, Jasón M, A. F. de Alencar (comp.). CLACSO: Buenos Aires.

Freire, P. (1997). Pedagogía de la autonomía. Buenos Aires: Siglo XXI.

Gargallo, F. (2008). "El feminismo y la educación en y para Nuestra América", Revista venezolana de estudios de la mujer, Caracas, 13(3). Recuperado de:

www.scielo.org.ve/scielo.php?script=sci_arttext\&pid=S1316-

$\underline{37012008000200003 \& \operatorname{lng}=e n \& n r m=i s o \text {. }}$

Gergen, K. J. (2000). Hacía un vocabulario para el diálogo transformador en Nuevos paradigmas en la resolución de conflictos: perspectivas y prácticas. Coord. Por D. Schnitman. Bs As, Arg Granica.

Kremer, L. (2012). Cuando escuchar no es suficiente. Los diálogos como posibilidad. Ponencia. In III Encuentro Latinoamericano de Metodología de las Ciencias Sociales (ELMeCS), Manizales Colombia.

Laaroussi, M., Lessard, D., Montejo, M. \& Viana, M. (1995). Méthodologie féministe et interculturelle: une alliance à facettes multiples. Recherches féministes, 8(2), pp.3146. Quebec, Canadá.

Martínez, L. C. P. (2010). Género y humor. La ironía y el relajo femenino en la búsqueda del sentido libertario. Debate Feminista. 21(41). México. Recuperado de: http://www.debatefeminista.com/PDF/Articulos/genero1255.pdf.

Maturana, H. (1994). El sentido de lo humano. Dolmen Editores, (4 ed.). Santiago de Chile

Maturana, H. Emociones y lenguaje en educación y política. Santiago de Chile: Hachette.

Morin, E. (1997). Réforme de pensée, transdisciplinarité, réforme de l'Université. Congrès International "Quelle Université pour demain? Vers une évolution transdisciplinaire, Suisse Motivation, 24.

Mozziconacci, V. (2016). "Teorías feministas de la educación: ¿dónde está el cuidado?” Educación y Socialización, 40. Recuperado em: http://journals.openedition.org/edso/1514. doi: 10.4000 / edso.1514.

Pearce, W. B. (1995). Nuevos modelos y metáforas comunicacionales: el pasaje de la teoría a la praxis del objetivismo al construccionismo social y de la representación a la reflexividad en Nuevos Paradigmas. Cultura y Subjetividad. In D. Schnitman. Buenos 
Aires, Argentina. Ed. Paidós

Pérez, A. A. et al. 2002 Didáctica de las prácticas escolares cotidianas. Preguntas a compartir con docentes de todos los niveles. Neuquén: Manuscritos.

Pérez, de L. N. (1996). "Feminismo, multiculturalismo y educación especial". Cuadernos de Pedagogía, Madrid, p. 253.

Savater, F. (2011). Ética para Amador. Barcelona: Ariel. $4^{\mathrm{a}}$ edic.

Schaffer, R. (2011). Desarrollo social Editorial Siglo XXI (México)

Silva, T. T. (1989). Interacción y socialización. Editorial Antonio Machado Madrid.

Silva, T. T. (1997). "Descolonizar el currículum: estrategias de una pedagogía crítica" en P. Gentili. (comp.). Cultura, política y currículo, Buenos Aires: Losada.

Schnitman, F. D. (2000). Introducción en Nuevos Paradigmas en la Resolución de Conflictos. Gránica.

Skliar, C. (2010) Procesos generativos en el diálogo: complejidad, emergencia y autoorganización. Revista Pensando la complejidad, VIII.

Skliar, C. (2005). "Poner en tela de juicio la normalidad, no la anormalidad" en $L a$ construcción social de la normalidad (BsAs: Novedades Educativas), 59.

Skliar, C. (2008) Conmover la educación. Ensayos para una pedagogía de la diferencia. BsAs Novedades Educativas.

Sinisi, L. (1999). "La relación nosotros-otros en espacios escolares multiculturales: estigma, estereotipo y racialización”. In M.R. Neufeld y J.A, Thisted. (comps.) De eso no se habla, los usos de la diversidad sociocultural en la escuela (Buenos Aires: Eudeba).

Stolkiner, A. (1987). De Interdisciplinas e Indisciplinas. In Elichiry, Nora (Comp.) El niño y la escuela. Reflexiones sobre lo obvio. Bs As: Ed. Nueva Visión, pp. 313-315.

Torres, A. (2003). Sistematizando experiencias de mujeres para el empoderamiento Una propuesta desde la práctica. Alforja Recuperado de:

http://www.cepalforja.org/sistem/documentos/sistematizando_experiencias_mujeres.pd.

Wigley, Marc. (1995). La deconstrucción del espacio en Nuevos Paradigmas. Cultura y Subjetividad. 